\title{
Food: An Unrecognized Source of Loop Diuretic Resistance
}

\begin{abstract}
Robert L. Bard, M.A., Barry E. Bleske, Pharm.D., and John M. Nicklas, M.D.
Food significantly affects the pharmacokinetics of oral loop diuretics in healthy individuals, but studies have not been performed in patients with edema. Because of this omission, food's effect on pharmacokinetics has been overlooked and may decrease the pharmacodynamic response in patients who rely on diuretics. Despite this potential interaction, reference manuals do not provide warnings about the effects of food on loop diuretic absorption. We reviewed the published human studies investigating the effects of food on loop diuretics. Peak plasma concentrations and urinary recovery were significantly decreased when taken with food, but only one study showed a corresponding decrease in total urine output, which is likely related to the diuretic threshold effect. These healthy subjects probably were always above the diuretic threshold under both fed and fasting conditions and thus could not augment their urine output. Based on these data in healthy subjects, the special implications for patients who routinely take diuretics are discussed. Therefore, food is more likely to have a clinical effect on the diuretic threshold given its effect in healthy subjects and the special considerations for patients with edema. Additional studies are needed to help answer these questions. Until such data are available, the most conservative, effective clinical approach is to administer oral loop diuretics without food.
\end{abstract}

Key Words: loop diuretics, furosemide, bumetanide, torsemide, edema.

(Pharmacotherapy 2004;24(5):630-637)

\section{OUTLINE}

Mechanism of Action of Loop Diuretics

Effects of Food on Loop Diuretics

Furosemide

Bumetanide

Torsemide

Discussion

Study Comparison

Correlation Between Pharmacokinetics and

Pharmacodynamics

Projections of Results from Healthy Subjects to

Patients

Conclusion

From the Division of Cardiovascular Medicine (Mr. Bard and Dr. Nicklas) and the College of Pharmacy (Dr. Bleske), University of Michigan Medical Center, Ann Arbor, Michigan.

Address reprint requests to Robert L. Bard, University of Michigan Medical Center, 1500 East Medical Center Drive, 3918 Taubman Center, Ann Arbor, MI 48109-0356; e-mail: bbard@umich.edu.
Loop diuretics are a common class of drug used in the treatment of chronic conditions such as chronic heart failure (CHF) and renal failure. Food has long been known to significantly affect the pharmacokinetics of loop diuretics. However, the clinical significance of these data is not appreciated nor well known.

\section{Mechanism of Action of Loop Diuretics}

The loop diuretics-furosemide, bumetanide, torsemide, and ethacrynic acid-act primarily and directly at the luminal surface of the ascending limb of the loop of Henle to prevent sodium chloride reabsorption from the tubule by inhibiting an ion transport protein sodiumpotassium-chloride symporter. These drugs are highly protein bound in the blood and do not enter the tubular lumen through glomerular filtration; they are secreted from the blood into 
the urine through the organic acid transport pathway in the straight segment of the proximal tubule. ${ }^{1}$ The transport pathway avidly secretes all loop diuretics and is relatively independent of the flow to the tubule. Only other organic acids, such as probenecid, alter loop diuretic secretion by competing for transport in the proximal tubule.

The inability to reabsorb salt in the loop region of the nephron results in a loss of the high medullary osmolality, thus decreasing the ability of the kidney to reabsorb water and helping to produce hypotonic urine. ${ }^{2}$ Loop diuretics reach the tubular lumen primarily as unmetabolized drug, and renal secretion accounts for the elimination of most of an administered dose, except in patients with advanced renal failure. The proximal tubule rapidly secretes loop diuretics, clearing the blood within hours and producing relatively short-lived periods of diuresis.

Loop diuretics also act indirectly to increase urine output by stimulating renal prostaglandin synthesis and vasodilating the prerenal arterioles. As a consequence, renal blood flow is increased, and the filtered sodium load at the tubule is increased; this allows the loop diuretic to prevent reabsorption of more sodium from the tubule. Diuretic effects can be limited by renal hypoperfusion and prostaglandin synthesis inhibitors, such as nonsteroidal antiinflammatory drugs. Such drugs can prevent one third of the increased renal blood flow attributed to loop diuretics.

In addition to the direct and indirect effects, the response to loop diuretics is determined by the rate of delivery of drug into the urine. To achieve an effective diuresis, a threshold concentration of diuretic must reach the site of action. The amount of drug must be sufficient to reach the steep portion of a sigmoid-shaped doseresponse curve (Figure 1). Once achieved, this is commonly referred to as reaching the diuretic threshold. Therefore, the pharmacodynamic response to diuretics is correlated with urinary diuretic excretion. ${ }^{1,3}$

Since urinary diuretic excretion correlates with diuresis, the amount of drug absorbed may directly affect the pharmacodynamic response. ${ }^{1,3}$ Although these drugs reach the tubular lumen by active secretion, drug concentrations in the blood drive the transport pathway in the proximal tubule. Based on this, diuretic efficiency as evaluated by urine drug concentration is dependent on drug absorption into the blood.
Thus, any alteration in drug absorption may alter the pharmacodynamic response.

Food is known to alter the absorption of a number of drugs and significantly affect the pharmacodynamic response. However, the effect of food on the absorption of oral loop diuretics has been overlooked, and it may affect the pharmacodynamic response. Despite this potential interaction, reference manuals, such as the Physicians' Desk Reference, ${ }^{4}$ do not provide warnings about the effects of food on loop diuretic absorption. In addition, neither physicians nor pharmacists commonly counsel patients about the timing of loop diuretic ingestion and meals, and some material ${ }^{5}$ instructs patients to take loop diuretics with meals. This is probably because a well-designed study has not been conducted involving patients who take diuretics for edema.

In some patients, food may prevent effective diuresis because the patients may be just above the diuretic threshold when they take their loop diuretics while fasting, but they may not reach diuretic threshold when they take their diuretics with food.

\section{Effects of Food on Loop Diuretics}

To examine the effects of food on the pharmacokinetics and pharmacodynamics of the oral loop diuretics, furosemide, bumetanide, and torsemide, we aggregated data from human studies. A literature review revealed eight published articles

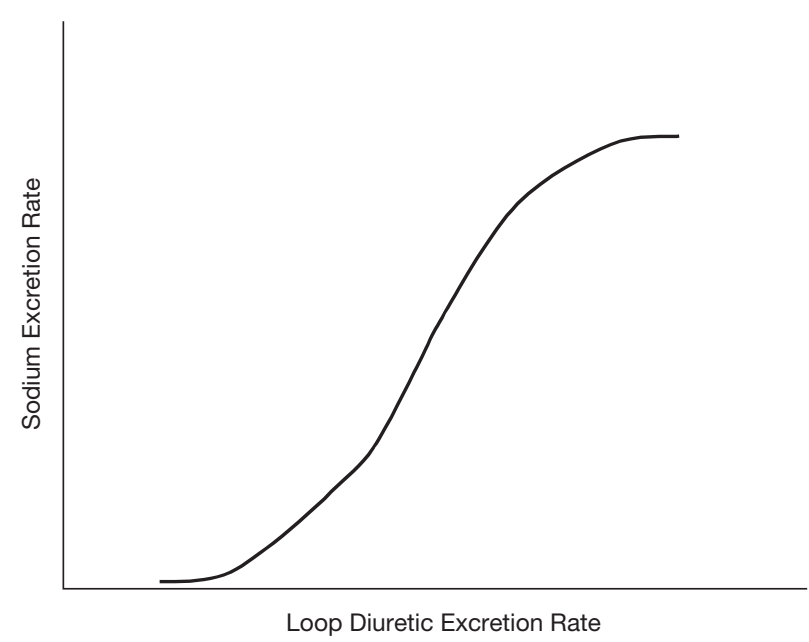

Figure 1. To achieve an effective diuresis, the amount of drug must be sufficient to reach the steep portion of a sigmoid-shaped dose-response curve like the one shown in this figure. Once achieved, this is commonly referred to as reaching the diuretic threshold. 
Table 1. A Review of the Methodology and Results of Studies Investigating the Effects of Food on Loop Diuretics

\begin{tabular}{|c|c|c|c|c|}
\hline \multirow[b]{2}{*}{$\begin{array}{l}\text { Drug, } \\
\text { Year of Study }\end{array}$} & \multicolumn{3}{|c|}{ Methodology } & \multirow[b]{2}{*}{$\begin{array}{l}\text { Food vs Fasting, } \\
\text { Formulation } \\
\text { (no. of patents) }\end{array}$} \\
\hline & $\begin{array}{c}\text { Study Participants, } \\
\text { Health Status } \\
\end{array}$ & $\begin{array}{l}\text { Dose } \\
(\mathrm{mg})\end{array}$ & Volume Replacement & \\
\hline $\begin{array}{l}\text { Furosemide } \\
1974^{7}\end{array}$ & 8 , healthy & 80 & i.v. Ringers by volume & $\begin{array}{l}\text { Fasting, tablet (5) } \\
\text { Meal, tablet (6) } \\
\text { Fasting, solution (6) } \\
\text { Meal, solution (2) }\end{array}$ \\
\hline $1985^{3}$ & 8 , healthy & 40 & Water $200 \mathrm{ml} / \mathrm{hr}$ & $\begin{array}{l}\text { Fasting, tablet } \\
\text { Meal, tablet } \\
\text { Meal, solution }\end{array}$ \\
\hline $1985^{9}$ & $\begin{array}{l}\text { 10, respiratory } \\
\text { failure }\end{array}$ & 40 & NA & $\begin{array}{l}30 \text { min preprandial, tablet } \\
30 \text { min postprandial, tablet }\end{array}$ \\
\hline $1986^{10}$ & 10, healthy & 40 & Water, $150 \mathrm{ml} / \mathrm{hr}$ & $\begin{array}{l}\text { Fasting, tablet (10) } \\
\text { Meal, tablet (10) }\end{array}$ \\
\hline $1995^{1}$ & 28 , healthy & 60 & Replaced volumes & $\begin{array}{l}\text { Heavy meal, tablet (5) } \\
\text { Fasting, Furix Retard } \\
\text { Meal, Furix Retard } \\
\text { Fasting, Lasix Retard } \\
\text { Meal, Lasix Retard }\end{array}$ \\
\hline $1996^{8}$ & 8 , healthy & 40 & $\begin{array}{l}\text { Water } 500 \mathrm{ml} \text { at hour } 1 \text {, then } \\
\text { i.v. sodium chloride by volume }\end{array}$ & $\begin{array}{l}\text { Fasting, solution } \\
\text { Meal, solution }\end{array}$ \\
\hline $\begin{array}{l}\text { Bumetanide } \\
1976^{6}\end{array}$ & $\begin{array}{l}\text { 6, healthy } \\
3, \mathrm{CHF}\end{array}$ & 1 & Constant between treatments & $\begin{array}{l}30 \text { min preprandial } \\
30 \text { min postprandial }\end{array}$ \\
\hline $1996^{8}$ & 9 , healthy & 2 & $\begin{array}{l}\text { Water } 500 \mathrm{ml} \text { at hour } 1 \text {, then } \\
\text { i.v. sodium chloride by volume }\end{array}$ & $\begin{array}{l}\text { Fasting, solution } \\
\text { Meal, solution }\end{array}$ \\
\hline $\begin{array}{c}\text { Torsemide } \\
1995^{11}\end{array}$ & 14 , healthy & 10 & Water ad libitum & $\begin{array}{l}\text { Fasting, tablet } \\
30 \text { min postprandial, tablet }\end{array}$ \\
\hline
\end{tabular}

$\overline{\mathrm{AUC}}=$ area under the concentration-time curve; $\mathrm{T}_{\max }=$ time to peak serum concentration of drug; $\mathrm{C}_{\max }=$ peak serum concentration of drug; $\mathrm{NA}=$ not available; $\mathrm{ND}=$ not done; Furix Retard, Lasix Retard = controlled-release formulations of furosemide.

aSignificantly different from fasting or preprandial $(\mathrm{p}<0.05)$.

bValues estimated from figures.

'Significantly different from Lasix retard $(\mathrm{p}<0.05)$.

over a span of 22 years that investigated the effects of food on loop diuretics (Table 1). ${ }^{1,3,6-11}$

\section{Furosemide}

Six of the eight published articles regarding food intake and loop diuretics evaluated furosemide. In 1974, the first study was published in which the primary focus was a comparison of aqueous and tablet forms of furosemide; the effect of food was a secondary aim. ${ }^{7}$ This study involved eight healthy volunteers under fasting and fed conditions. However, not all participants completed all arms of the study; only two subjects ingested the solution with a meal and the other three arms had six or fewer subjects.

Subjects took oral furosemide $80 \mathrm{mg}$ after breakfast; urine losses were replaced with Ringer's lactate solution. Blood was obtained for pharmacokinetic studies for a total of 4 hours 40 minutes. Urine was collected, but urinary recovery was not reported because of errors in the assay system.

Food significantly impaired furosemide absorption, as demonstrated by the maximum concentration of drug $\left(\mathrm{C}_{\max }\right)$ and the time to $\mathrm{C}_{\max }\left(\mathrm{T}_{\max }\right)$. In fact, $\mathrm{C}_{\max }$ was more than double in the fasting versus the fed group in subjects who took furosemide in tablet form. Despite 
Table 1. (continued)

\begin{tabular}{|c|c|c|c|c|c|c|c|}
\hline \multirow{2}{*}{\multicolumn{6}{|c|}{ Pharmacokinetics }} & \multirow{2}{*}{\multicolumn{2}{|c|}{ Pharmacodynamics }} \\
\hline & & & & & & & \\
\hline \multicolumn{3}{|c|}{ Urinary Recovery } & \multicolumn{3}{|c|}{ Absorption in Blood } & \multirow{2}{*}{$\begin{array}{c}\text { Diuresis } \\
(\mathrm{ml})\end{array}$} & \multirow{2}{*}{$\begin{array}{c}\text { Time Interval } \\
\text { (hrs) }\end{array}$} \\
\hline Time (hrs) & $(\mathrm{mg})$ & $\%$ of Dose & $\mathrm{AUC}(\mathrm{mg} \bullet \mathrm{hr} / \mathrm{L})$ & $\mathrm{T}_{\max }(\mathrm{hrs})$ & $\mathrm{C}_{\max }(\mathrm{mg} / \mathrm{L})$ & & \\
\hline 4 & NA & NA & 3.93 & 1.0 & $2.3 \pm 0.5$ & $5144 \pm 1752$ & 12 \\
\hline 4 & NA & NA & ND & $2.0^{\mathrm{a}}$ & $1.0^{\mathrm{a}}$ & $4836 \pm 1304$ & 12 \\
\hline 4 & NA & NA & 4.15 & NA & NA & $4037 \pm 1179$ & 12 \\
\hline 4 & NA & NA & ND & NA & NA & $5180 \pm 764$ & 12 \\
\hline 8 & $14.0 \pm 1.1$ & $35 \pm 3$ & ND & ND & ND & $1950 \pm 88$ & 8 \\
\hline 8 & $9.5 \pm 0.4^{\mathrm{a}}$ & $24 \pm 1^{a}$ & ND & ND & ND & $2130 \pm 185$ & 8 \\
\hline 8 & $9.2 \pm 0.8^{\mathrm{a}}$ & $23 \pm 2^{a}$ & ND & ND & ND & $2250 \pm 110$ & 8 \\
\hline 6 & 8.03 & 20 & 3.99 & $0.5^{\mathrm{b}}$ & 3.99 & 867 & 6 \\
\hline 24 & 11.55 & 29 & ND & ND & ND & 1689 & 24 \\
\hline 6 & 6.35 & 16 & $2.71^{\mathrm{a}}$ & $3.0^{\mathrm{b}}$ & $2.71^{\mathrm{a}}$ & 980 & 6 \\
\hline 24 & 9.41 & 24 & ND & ND & ND & 1753 & 24 \\
\hline \multirow[t]{2}{*}{48} & $11.4 \pm 2.5$ & $29 \pm 6$ & $2.174 \pm 0.668$ & 1.4 & $0.933 \pm 0.272$ & $2072 \pm 347$ & 10 \\
\hline & & & & & & $2668 \pm 691$ & 24 \\
\hline \multirow[t]{2}{*}{48} & $8.4 \pm 1.4^{\mathrm{a}}$ & $21 \pm 4^{a}$ & $1.219 \pm 0.153^{\mathrm{a}}$ & 1.4 & $0.423 \pm 0.153^{a}$ & $1640 \pm 347$ & $10^{\mathrm{a}}$ \\
\hline & & & & & & $2270 \pm 397$ & $24^{a}$ \\
\hline 48 & $8.8 \pm 1.8^{\mathrm{a}}$ & $22 \pm 5^{a}$ & $1.169 \pm 0.313^{\mathrm{a}}$ & $2.2^{\mathrm{a}}$ & $0.356 \pm 0.062^{\mathrm{a}}$ & NA & NA \\
\hline 24 & $11.38 \pm 3.12^{c}$ & $19 \pm 5$ & ND & ND & ND & $4096 \pm 1281$ & 24 \\
\hline 24 & $7.73 \pm 1.67^{\mathrm{a}, \mathrm{c}}$ & $13 \pm 3$ & ND & ND & ND & $3817 \pm 1283$ & $24^{c}$ \\
\hline 24 & $8.04 \pm 3.32$ & $13 \pm 6$ & ND & ND & ND & $3436 \pm 1259$ & 24 \\
\hline 24 & $9.45 \pm 1.83^{\mathrm{a}}$ & $16 \pm 3$ & ND & ND & ND & $4347 \pm 1374$ & $24^{a}$ \\
\hline 24 & $18.16 \pm 3.16$ & $45 \pm 8$ & $3.54 \pm 0.82$ & $0.69 \pm 0.21$ & $2.35 \pm 0.49$ & ND & ND \\
\hline 24 & $11.84 \pm 2.44^{\mathrm{a}}$ & $30 \pm 6 a$ & $1.95 \pm 0.72^{\mathrm{a}}$ & $1.91 \pm 0.93^{\mathrm{a}}$ & $0.51 \pm 0.19^{\mathrm{a}}$ & ND & ND \\
\hline NA & NA & NA & NA & NA & NA & NA & NA \\
\hline NA & NA & NA & NA & NA & NA & NA & NA \\
\hline 24 & $1.19 \pm 0.168$ & $60 \pm 8$ & $0.143 \pm 0.023$ & $0.53 \pm 0.08$ & $0.097 \pm 0.015$ & ND & ND \\
\hline 24 & $1.00 \pm 0.312^{\mathrm{a}}$ & $50 \pm 16^{a}$ & $0.126 \pm 0.025$ & $1.36 \pm 0.72^{\mathrm{a}}$ & $0.036 \pm 0.012^{\mathrm{a}}$ & ND & ND \\
\hline 24 & $2.37 \pm 0.62$ & $24 \pm 6$ & $3.357 \pm 0.859$ & $0.89 \pm 0.37$ & $1.466 \pm 0.202$ & $5000 \pm 1100$ & 24 \\
\hline 24 & $2.35 \pm 0.43$ & $24 \pm 4$ & $3.424 \pm 0.841$ & $1.50 \pm 0.64^{\mathrm{a}}$ & $0.988 \pm 0.269^{a}$ & $4700 \pm 1400$ & 24 \\
\hline
\end{tabular}

significant pharmacokinetic differences, diuresis was similar in the two groups. This disparity between pharmacokinetics and pharmacodynamics probably occurred because the healthy participants were all above diuretic threshold under both fed and fasting conditions; thus, greater concentrations of drug could not produce significant changes in urine output.

More than a decade later, a 1985 study evaluated the effect of food with furosemide in eight healthy volunteers. ${ }^{3}$ As in the study discussed above, ${ }^{7}$ the primary purpose was to compare different forms of furosemide. Subjects took the drug in tablet and aqueous forms with food, and in tablet and intravenous forms while fasting. Methodologic differences were noted between fasting and fed conditions. Under fasting conditions oral furosemide $40 \mathrm{mg}$ was taken with $200 \mathrm{ml}$ of water, but under fed conditions it was taken with $200 \mathrm{ml}$ of orange juice after a meal that included tea. In contrast, other food and diuretic studies excluded xanthine-containing foods.

Urine was collected at regular intervals over 8 hours; pharmacokinetic studies of the blood were not performed. Significantly less furosemide was present in the urine during fed conditions $(\mathrm{p}<0.01)$. Despite greater concentrations of drug while fasting, the average diuresis was greater in fed subjects, although the difference was not statistically significant. It is unknown why there was not a better correlation between urinary excretion of furosemide and diuresis. A potential confounding factor in this study was the coadministration of different liquids with furosemide between the fed and fasting phases. Tea may have affected diuresis under the fed condition. Despite these differences, the amount 
of drug excreted by the kidney was lower in the group who took furosemide with food.

Another 1985 study is the only one that involved subjects other than healthy volunteers. ${ }^{9}$ A subset of 10 patients with respiratory failure received oral furosemide $40 \mathrm{mg} 30$ minutes before or after breakfast. This small study evaluated the short-term diuretic effect. Serum concentrations of furosemide were measured at $0.5,1.5,3.0$, and 6.0 hours after diuretic ingestion. The authors concluded that furosemide taken before a meal improved absorption, as demonstrated by a significantly greater area under the concentration-time curve (AUC), $\mathrm{T}_{\max }$, and $\mathrm{C}_{\max }(\mathrm{p}<0.01$ for all three). Diuresis was similar between the two groups; however, fluid replacement during the study was not addressed.

A year later, a study involving 10 healthy volunteers reported a reduced effect of oral furosemide $40 \mathrm{mg}$ when given with food. ${ }^{10}$ Subjects ingested furosemide on separate days at least 1 week apart, with or without a meal. The effects of a heavy breakfast were studied in a subset of five of the subjects. Blood was sampled over 10 hours, and urine was collected for up to 48 hours. Food significantly decreased both $C_{\max }$ and urine production $(\mathrm{p}<0.05)$. Subjects taking furosemide with food had significantly smaller urinary recovery of the drug, which was consistent with the significantly decreased plasma AUC and $C_{\max }$ values.

A $21 \%$ greater diuresis occurred at 10 hours under the fasting versus fed condition. The pharmacokinetic and pharmacodynamic effects of the heavy meal were nearly identical to those of the standard meal, except that the heavy meal increased the average $\mathrm{T}_{\max }$ from 1.4 to 2.2 hours. Based on these data, the authors concluded that furosemide should not be given with food.

Another decade passed before a 1995 study was published that involved furosemide $60 \mathrm{mg}$ administered with food in 28 healthy subjects. ${ }^{1}$ As in other studies, determining the effect of food was not the only aim. This study compared the effect of food on two different controlled-release formulations of furosemide (Furix Retard and Lasix Retard, neither of which has been approved by the Food and Drug Administration). Subjects took furosemide while fasting or immediately after consuming a high-fat breakfast. Urine samples were obtained over 24 hours; blood samples were not obtained.

Differences were observed between the two furosemide formulations. When taken under fasting conditions, urinary furosemide was greater with Furix Retard than Lasix Retard. Twenty-four hour urine volume was significantly greater when subjects took Lasix Retard with food, but no significant difference was noted with Furix Retard. The reason for this discrepancy is unclear; the authors speculated that there may be some type of difference in the capsule-coating material of the two products.

The most recent study involving food and furosemide, published in 1996, evaluated furosemide $40 \mathrm{mg}$ and bumetanide $2 \mathrm{mg}$ in two different crossover trials of healthy volunteers. ${ }^{8}$ Subjects underwent four different studies in a randomized, crossover design that incorporated the two factors: fasting or fed conditions and oral or intravenous forms of the drug taken. Subjects took the drug while fasting or immediately after eating breakfast. The oral furosemide was given as an aqueous solution in $100 \mathrm{ml}$ of orange squash and then was washed down with $100 \mathrm{ml}$ of water.

Blood and urine were collected at regular intervals over the first 8 hours; urine collection was continued until 24 hours after dose administration. Only urinary drug content was reported since the study was not controlled to consider pharmacodynamic effects. Taking the drug with food was associated with a 30\% decrease in bioavailability. Also, it significantly decreased urinary recovery of furosemide $(\mathrm{p}<0.001), \mathrm{C}_{\max }(\mathrm{p}<0.001)$, and AUC $(\mathrm{p}<0.01)$, and significantly increased $\mathrm{T}_{\max }(\mathrm{p}<0.01)$. One methodologic difference between this and the other studies is that the subjects remained supine for the entire study (except when urinating). This is an important variable to consider because body position affects renal blood flow and thus can affect diuresis.

\section{Bumetanide}

Two studies have evaluated the effect of food on bumetanide pharmacokinetics. ${ }^{6,8}$ The first was presented in extended abstract form and provided scant data. ${ }^{6}$ The study was designed to minimize the need to urinate after retiring to bed, so bumetanide was taken either 30 minutes before or immediately after dinner. Urine volumes were obtained hourly for 6 hours; blood samples were not obtained. No difference was noted in total urine volumes, but there was a significant difference in the pattern of diuresis. Urine output the first hour was greater under preprandial conditions, and diuresis was largely 
completed within 3 hours in those who took bumetanide before versus after dinner. The authors concluded that patients are less likely to interrupt their sleep to urinate when loop diuretics are taken before rather than after dinner.

The second study, described earlier, involved bumetanide in a crossover with furosemide. ${ }^{8}$ Nine healthy men were given bumetanide $2 \mathrm{mg}$ as a solution, with or without food. As with furosemide, bumetanide significantly decreased $\mathrm{C}_{\max }(\mathrm{p}<0.001)$ and increased $\mathrm{T}_{\max }(\mathrm{p}<0.05)$ but had less effect on other pharmacokinetic parameters (Table 1). Bioavailability, AUC, and urinary recovery were decreased when bumetanide was taken with food, but the differences did not reach statistical significance. Therefore, the authors concluded that food is a factor that may influence the potency or pattern of diuresis, but the effect may be less with bumetanide.

\section{Torsemide}

In the only study evaluating the effect of food on torsemide pharmacokinetics, 14 healthy volunteers participated in a 24-hour, open-label study of oral torsemide $10 \mathrm{mg}$ taken in fasting condition or 30 minutes after a meal. ${ }^{11}$ Patients were permitted to drink water ad libitum, and urine was collected over the 24-hour study period. The food condition involved a high-fat, high-carbohydrate meal. Plasma samples obtained at intervals up to 24 hours for pharmacokinetics indicated that $\mathrm{C}_{\max }$ decreased $(\mathrm{p}<0.001)$ and $\mathrm{T}_{\max }$ increased $(\mathrm{p}=0.013)$ when torsemide was taken with food. However, no significant difference was noted in AUC $(p=0.452)$ or urinary excretion $(p=0.820)$ over the 24-hour study period. The maximum urinary excretion rate of torsemide was significantly lower in the fed group, but this difference was not reflected in urine output at 24 hours (5.0 \pm $1.1 \mathrm{~L}$ fasting vs $4.7 \pm 1.4 \mathrm{~L}$ fed). These data suggest that food decreases the rates of absorption and urinary excretion of torsemide.

\section{Discussion}

This review yielded evidence demonstrating that food affects the pharmacokinetics of loop diuretics. The glaring omission in the review is a quality study involving patients with CHF. The absence of such a study in the published literature indicates that the effect of food on loop diuretics in patients with edema has been ignored. Among the available studies, the differences in both methodology and results are profound.

\section{Study Comparison}

The studies reviewed used different doses and forms of diuretics, meals, sampling intervals, and fluid replacement strategies. These limitations were further compounded by small sample sizes and studies in which the effect of food was not the primary outcome. One study appeared to provide the best information because it answered the most concerns. ${ }^{10}$ The effect of food was the primary outcome, and the study used the most common diuretic (furosemide) in its most common oral form. Many of the other furosemide studies involved questionable methodologies with very small samples, different primary aims, unavailable or uncommon forms of the drug, or missing pharmacokinetic or pharmacodynamic data. In addition, scant data are available regarding bumetanide and torsemide.

Most studies demonstrated a significant decrease in the rate and extent of loop diuretic absorption along with a decrease in urinary excretion (Table 1). The effects were greatest in studies comparing participants in both the fasting and fed states, but pharmacokinetic differences also were reported when comparing loop diuretic ingestion before versus after a meal.

\section{Correlation Between Pharmacokinetics and Pharmacodynamics}

The pharmacokinetic variable of interest regarding loop diuretics is the amount of drug recovered in the urine since the drug passes through its active site of action. One reason for ignoring the food issue may be that clinicians focus on urine output and not urinary drug concentration. With loop diuretics, urinary drug content does not always correlate with urinary volumes because of the threshold effect.

Every study found that food significantly decreased the absorption of loop diuretic into the blood, but only one ${ }^{10}$ reported a corresponding decrease in urinary output. This discrepancy may be explained by situations in which the doses were above diuretic threshold. Regardless of the amount of drug recovered in the urine, more urine could not be produced because the threshold was surpassed under both the fed and fasting conditions. A dose-ranging trial involving these subjects could help determine the effect of food on urine volume by giving a dose when the 
blunted diuretic absorption with food is below threshold, but the fasting absorption remains above threshold.

Another concern is the urine collection time points. The period of clinical importance is approximately the first 6 hours. During this period, loop diuretics have their maximal effect, and clinical decisions are likely to be made. In the above study, ${ }^{10}$ urine output was separated over 1-hour periods, and the greatest difference occurred over the first 5 hours. In addition, both this study and another study ${ }^{1}$ reported that subjects who took furosemide with food never made up for the lost diuresis after 24 hours.

Projections of Results from Healthy Subjects to Patients

Healthy subjects have superior absorption ability compared with patients with CHF or renal disease. Loop diuretics are a primary therapy for patients with CHF, whose ability to absorb diuretics is impaired compared with healthy subjects, especially when decompensated. As displayed in Figure 2, patients with $\mathrm{CHF}$ have lower $\mathrm{C}_{\max }$ and longer $\mathrm{T}_{\max }$ than healthy subjects, ${ }^{12-17}$ which translates into a decreased ability to transport drug into the urine compared with healthy subjects. ${ }^{14,15,18}$ These effects are likely to be multifactorial and may be explained by delayed gastric emptying, decreased gastrointestinal motility, decreased renal function, and bowel wall edema associated with $\mathrm{CHF}^{11,13,14,19-23}$

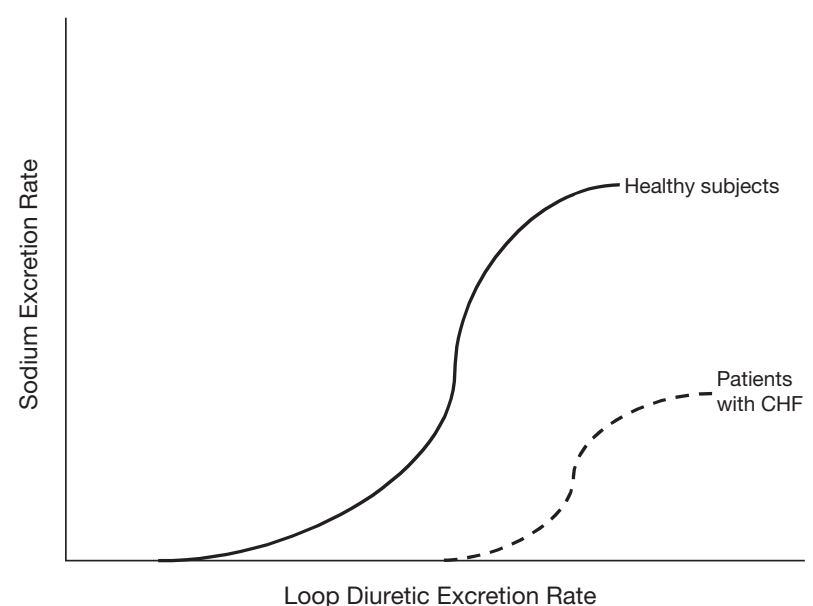

Figure 2. As seen in these dose-response curves, patients with chronic heart failure (CHF) have a lower $\mathrm{C}_{\max }$ and longer $\mathrm{T}_{\max }$ than healthy subjects, ${ }^{12-17}$ which translates into a decreased ability to transport drug into the urine when compared with healthy subjects.
Theoretically, patients who take their diuretic with food can alter diuretic absorption and put themselves at even greater risk because they do not achieve diuretic threshold. Under fasting conditions the diuretic is appropriately absorbed, but a meal may be a significant barrier that prevents patients from obtaining diuretic threshold, since every study in this review showed that food significantly decreased $\mathrm{C}_{\max }$.

Many patients who are prescribed diuretics also have compromised renal function as a consequence of their disease, aging, or a combination of the two. Aging itself is associated with decreased renal function and has been the primary factor associated with age-related pharmacokinetic differences with the loop diuretics, furosemide, ${ }^{15}$ bumetanide,${ }^{24}$ and torsemide. ${ }^{25}$ With renal insufficiency and aging, the decreased access of drug to the site of action warrants larger doses of diuretics to elicit a response. ${ }^{26}$ Again, as in patients with heart failure, any decrease in the amount of diuretic absorbed may result in not reaching diuretic threshold and consequent fluid retention. The amount of diuretic absorbed is critical for patients with renal insufficiency, and administration of diuretics with food may hinder their therapy.

These findings may have clinical implications for patients with heart failure and renal failure since they are highly dependent on loop diuretics for fluid control, and any factor that leads to fluid retention commonly leads to hospitalizations. Administration of food and loop diuretics together may significantly reduce the rate of absorption and the amount of drug that reaches the kidney, potentially decreasing diuretic efficacy. As opposed to patients who have eaten, those who are fasting are more likely to experience optimal diuretic pharmacokinetics (shorter $\mathrm{T}_{\max }$ and greater $\mathrm{C}_{\max }$ ) and pharmacodynamics. Thus, administering loop diuretics without food maximizes the chances of achieving a diuretic response to a given dose.

\section{Conclusion}

The administration of food and loop diuretics together may significantly alter the rate of absorption and the amount of drug that reaches the kidney. Clinically, this suggests that the most effective mode of administering loop diuretics is without food. Fasting can be important in optimizing the ability to reach diuretic threshold and expediting a response, allowing the clinician 
to make timely decisions regarding the patient's need for hospitalization and intravenous diuretics. Overall, the data suggest that administering loop diuretics without food will give clinicians the best chance of having patients achieve a diuretic response to a given dose.

\section{References}

1. Paintaud G, Alvan G, Eckernas SA, Wakelkamp M, Grahnen A. The influence of food intake on the effect of two controlled release formulations of furosemide. Biopharm Drug Dispos 1995; 16(3):221-32.

2. Ponto LL, Schoenwald RD. Furosemide (frusemide). A pharmacokinetic-pharmacodynamic review (part I). Clin Pharmacokinet 1990;18(5):381-408.

3. Hammarlund MM, Odlind B, Paalzow LK. Acute tolerance to furosemide diuresis in humans: pharmacokinetic-pharmacodynamic modeling. J Pharmacol Exp Ther 1985;233(2):447-53.

4. Anonymous. Loop diuretics. Physicians' desk reference, 55th ed. Montvale, NJ: Medical Economics, 2001

5. Micromedex. Furosemide. In: DrugPoints system, vol 117. Greenwood Village, CO: Micromedex healthcare series, 1998.

6. Homeida M, Hunter K, Roberts C. Delayed response to oral bumetanide given after a meal. Br J Clin Pharmacol 1976;30: 969-70.

7. Kelly MR, Cutler RE, Forrey AW, Kimpel BM. Pharmacokinetics of orally administered furosemide. Clin Pharmacol Ther 1974;15(2):178-86.

8. McCrindle JL, Li Kam Wa TC, Barron W, Prescott LF. Effect of food on the absorption of furosemide and bumetanide in man. Br J Clin Pharmacol 1996;42(6):743-6.

9. Ogata H, Kawatsu Y, Maruyama Y, Machida K, Haga T. Bioavailability and diuretic effect of furosemide during longterm treatment of chronic respiratory failure. Eur J Clin Pharmacol 1985;28(1):53-9.

10. Beermann B, Midskov C. Reduced bioavailability and effect of furosemide given with food. Eur J Clin Pharmacol 1986; 29(6):725-7.

11. Kramer WG. Effect of food on the pharmacokinetics and pharmacodynamics of torsemide. Amer J Ther 1995;2:499-503.
12. Brater DC, Chennavasin P, Seiwell R. Furosemide in patients with heart failure: shift in dose-response curves. Clin Pharmacol Ther 1980;28(2):182-6

13. Brater DC, Day B, Burdette A, Anderson S. Bumetanide and furosemide in heart failure. Kidney Int 1984;26(2):183-9.

14. Vasko MR, Cartwright DB, Knochel JP, Nixon JV, Brater DC. Furosemide absorption altered in decompensated congestive heart failure. Ann Intern Med 1985;102(3):314-18

15. Hammarlund-Udenaes M, Benet LZ. Furosemide pharmacokinetics and pharmacodynamics in health and disease: an update. J Pharmacokinet Biopharm 1989;17(1):1-46.

16. Kramer WG. Pharmacokinetics and pharmacodynamics of torsemide in congestive heart failure. Cardiol 1994;84(suppl 2):108-14.

17. Vargo DL, Kramer WG, Black PK, Smith WB, Serpas T, Brater DC. Bioavailability, pharmacokinetics, and pharmacodynamics of torsemide and furosemide in patients with congestive heart failure. Clin Pharmacol Ther 1995;57(6):601-9.

18. Brater DC, Seiwell R, Anderson S, Burdette A, Dehmer GJ, Chennavasin P. Absorption and disposition of furosemide in congestive heart failure. Kidney Int 1982;22(2):171-6.

19. Ponto LL, Schoenwald RD. Furosemide (frusemide). A pharmacokinetic-pharmacodynamic review (part II). Clin Pharmacokinet 1990;18(6):460-71.

20. Benet LZ. Pharmacokinetics-pharmacodynamics of furosemide in man: a review. J Pharmacokinet Biopharm 1979;7(1):1-27.

21. Benowitz NL, Meister W. Pharmacokinetics in patients with cardiac failure. Clin Pharmacokinet 1976;1(6):389-405.

22. Greither A, Goldman S, Edelen JS, Benet LZ, Cohn K. Pharmacokinetics of furosemide in patients with congestive heart failure. Pharmacology 1979;19(3):121-31.

23. Johnston D, Duffin D. Drug-patient interactions and their relevance in the treatment of heart failure. Amer J Cardiol 1992;70(10):109C-12.

24. Oberbauer R, Krivanek P, Turnheim K. Pharmacokinetics and pharmacodynamics of the diuretic bumetanide in the elderly. Clin Pharmacol Ther 1995;57(1):42-51.

25. Barr WH, Smith H, Karnes H, et al. Comparison of bioavailability, pharmacokinetics and pharmacodynamics of torsemide in young and elderly healthy volunteers. Prog Pharmacol Clin Pharmacol 1990;8:15-28.

26. Brater DC. Resistance to loop diuretics: why it happens and what to do about it. Drugs 1985;30(5):427-43. 